\title{
A SIMPLIFICAÇÃO DOS PROCESSOS DE PRODUÇÃO EM INDÚSTRIA AUTOMOBILÍSTICA
}

\author{
Carlos Daniel Pinto Coelho, MSc. (ICE- MG); \\ Lisiane Ilha LIbrelotto, Dra. (UFSC)
}

\author{
PALAVRAS-CHAVE \\ Simplificação. Processos. Produção. \\ KEYWORDS \\ Simplification. Processes. Production
}

\section{RESUMO:}

Este artigo apresenta os resultados parciais da dissertação de mestrado profissionalizante sobre o desenvolvimento de um método de análise da padronização de componentes empregados na produção dos vários tipos de modelos de veículos para uma indústria automobilística. O método propositivo objetivou a redução da complexidade nos processos da indústria automobilística, frente à tendência crescente do número de peças similares com a mesma função na composição dos veículos decorrente da variação do mix de produtos pelo design. Para realização da pesquisa foram analisadas diversas situações em que a diferenciação do produto implicou o aumento da complexidade dos processos. Como resultados obteve-se um método para simplificação dos processos e o apontamento dos principais benefícios obtidos com a melhoria.

\section{ABSTRACT:}

This article presents the partial results of a master's degree dissertation about the development of an automotive components standardization analysis method for an automotive industry. The propositional method aimed to reduce the complexity of processes of the automotive industry due to the rising trend of a number of similar parts with the same use in the vehicles assembly due to mix products variation made by Design Area. In order to conduct the survey several situations in which the product differentiation caused the increasing of complexity in the process were analyzed. As a result a simplifying method was obtained as well as the main benefits of the improvement. 


\section{INTRODUÇÃO}

Em uma indústria automobilística, os processos de produção e de gestão dos materiais diretos empregados na fabricação dos veículos são de natureza complexa, porque lidam com muitas variáveis. Destaca-se a gestão de peças muito parecidas com a mesma função, como porcas, parafusos, arruelas, entre outros e mesmo peças maiores com pequenas variações. Administrar a diversidade desse tipo de componentes e garantir a montagem de todos eles nos vários tipos de veículos, versões e opcionais, exatamente como previsto pelos documentos técnicos, não é uma tarefa fácil ou precisa.

A diferenciação do produto é uma estratégia de marketing e design e conduz ao desenvolvimento de uma série de componentes distintos, às vezes com a mesma função, para atender aos diversos modelos previstos.

Segundo Filho (1999) APUD WIEMES e Balbinotti (2009), a padronização pode oferecer diversos benefícios qualitativos e quantitativos. Para Campos (1999), as empresas modernas devem considerar a padronização como a mais fundamental das ferramentas gerenciais. Este autor, ao explicar o que é padronização, lembra que as pessoas fazem as coisas de várias formas, mas, quando alguém faz de um jeito melhor, os outros, imediatamente, adotam a ideia, ou seja, padronizam.

Diminuir o número de peças muito parecidas com a mesma função traz vantagens e benefícios, decorrentes da eliminação das possibilidades de erros operacionais na montagem dos veículos; redução do estoque e de espaços físicos com a armazenagem dos materiais; simplificação das atividades de programação, de compra, de aprovisionamento e de movimentação dos materiais na cadeia de suprimentos; menor geração de resíduos sólidos e de gás carbônico $\left(\mathrm{CO}_{2}\right)$; maior sustentabilidade da cadeia de suprimentos.

Mudar a cultura de que a padronização prejudica a customização dos produtos, que contribui para a perda da atratividade de venda e que não aumenta o custo dos veículos é uma tarefa difícil, como, também, não é fácil demonstrar contabilmente os ganhos e benefícios. A padronização de componentes não pode prejudicar as inovações da marca exigidas pelo mercado, nem as concepções técnicas e soluções de projeto e nem as estratégias de compras. Ela requer cuidado e muita atenção às necessidades das várias partes interessadas, como estratégias diferenciadas para cada proposta, novo olhar e visão sistêmica.

Este artigo apresenta o resultado de uma pesquisa, conduzida em mestrado profissionalizante (COELHO, 2013) que se justifica pela possibilidade de construção de caminhos visando a redução das perdas da complexidade e a obtenção de ganhos e benefícios com a diminuição do número de componentes automotivos, sem prejudicar a necessária customização dos produtos e a perda da atratividade das vendas.

O objetivo da pesquisa foi investigar se a estandardização de peças está contribuindo para a simplificação dos processos de produção e de gestão dos materiais e para a redução da complexidade da fábrica.

\section{DESENVOLVIMENTO}

\subsection{O PROBLEMA DA PESQUISA}

Por mais precisa que seja a individualização das peças que compõem um automóvel, é comum ocorrer montagens indevidas. Só de volantes para um novo modelo, na montadora pesquisada, há 28 tipos diferentes, devido às opções de teclas comando rádio no volante, de revestimento em couro e de cinco tonalidades de cor cinza para a moldura central do volante. De chicotes (feixe de cabos elétricos), há uma infinidade de combinações, de acordo com as composições que os clientes escolhem nas opções de personalização do veículo no site da empresa.

O uso divergente de peças afeta os níveis de desempenho dos serviços, como demons- 
tram os indicadores de eficiência referentes a veículos incompletos, a materiais obsoletos, ao capital circulante, aos saldos negativos de estoque e ao aumento do movimento de caminhões com transportes especiais. A existência de peças muito parecidas com a mesma aplicação exige cuidados especiais com a sua gestão, pois a probabilidade de erros operacionais é grande. Além disso, mais componentes ocupam mais espaço físico para armazenamento. Isso afeta o desempenho dos empregados que lidam com as atividades de programação, de compra, de aprovisionamento e de movimentação dos materiais, desde o início com os fornecedores, passando pela fábrica até o final nas concessionárias e nos clientes.

No setor de peças das concessionárias, os clientes podem ser atendidos com peças de reposição diferentes das corretas, devido à dificuldade de individualização da peça certa no momento da venda. Sendo assim, tornou-se consenso geral de que a padronização de componentes é uma necessidade a ser atendida para a melhoria dos níveis de serviços prestados pelas áreas de apoio e para a simplificação dos processos.
Hubbard (2009), no livro "Como mensurar qualquer coisa", demonstra que é possível medir aspectos considerados intangíveis em muitas organizações, como a satisfação do cliente, a flexibilidade organizacional e o retorno sobre o investimento da tecnologia. Ele mostra um novo modo de encarar a intangibilidade com novas formas de abordagem de problemas. Assim, seguramente e mais facilmente muitas propostas de padronização de componentes seriam aprovadas, mesmo com a necessidade de atendimento das exigências de cada área.

\subsection{A VISÃO SISTÊMICA NECESSÁRIA À EQUAÇÃO}

Slack, Chambers e Johnston (2002, p.55) afirmam que os limites funcionais não devem prejudicar a eficiência dos processos internos e é preciso trabalhar junto com outras partes da organização para se formar as responsabilidades indiretas mais importantes da adminis-

Figura 1 - Tubos de direção hidráulica.

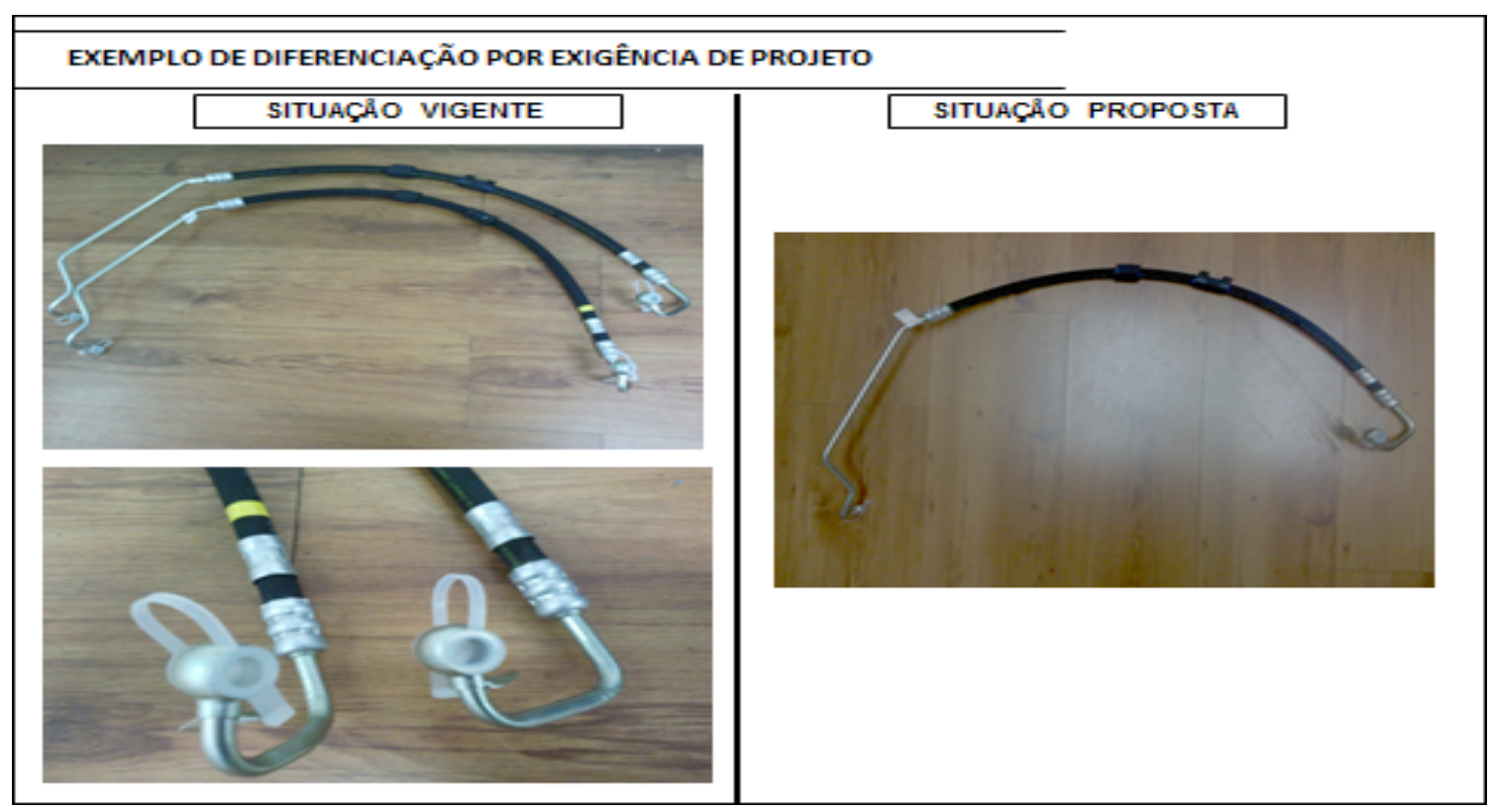

Fonte: Autores.

'Saldos negativos de estoque ocorrem quando se produz uma quantidade maior de veículos do que as peças existentes em estoque, mostrando, com isso, um erro de inventário, de lançamento nas entradas, ou nas saídas dos materiais, etc... tração da produção.

Da necessidade de atendimento às exigências de cada área, resulta a dificuldade de aprovação das propostas de padronização de 
componentes. Devido a isso, muitas são reprovadas pelo Produto, por razões de estilo, ou pela Engenharia, por razões técnicas ou por Compras, por razões econômicas. É necessário reavaliar as questões das outras áreas, dando-lhes pesos justos e procurando o devido equilíbrio das variáveis em jogo para que a redução da complexidade se torne realidade. Para Slack, Chambers e Johnston (2002, p.55), "desenvolver e melhorar os relacionamentos entre a produção e as outras funções da empresa deveria ser a contribuição central da produção para o desempenho geral."

A Figura 1 mostra os tubos da direção hidráulica extremamente semelhantes, diferenciados apenas pela curvatura suave em uma das pontas. Era, por isso, frequente o uso de uma peça no lugar da outra. Neste caso, a Engenharia concordou com a revisão do projeto e providenciou o desenho de um terceiro tubo que atendesse às duas aplicações previstas, eliminando o problema de erro operacional.

\subsection{A COMPLEXIDADE DA FÁBRICA}

Morin (2006) explica que existe uma tendência de prender a realidade a um sistema coerente - o que se chama de racionalização - e que tudo o que contradiz este sistema, é afastado, esquecido, posto de lado e visto como ilusão ou aparência. Segundo ele, existe, então, uma tendência inconsciente de afastar da mente o que possa contradizê-la.

Foram aliadas à ideia, a oportunidade de agregação de valor e de aumento da competitividade que a atividade do processo de redução da complexidade da fábrica representaria para a empresa e para os fornecedores. Por isso, teve-se a visão de que a diminuição do número de componentes, além de simplificar, seria também um fator de redução de custo e a diversificação de desenhos seria um fator de aumento da complexidade, que provoca erros operacionais, dificulta as práticas de trabalho e gera perdas produtivas e desperdícios nos processos.

Ter um número de desenho só é melhor do que ter dois e que isso deve custar menos para a empresa e para os fornecedores. Assim a essência desta pesquisa foi unificar o maior número possível de peças similares, ou muito parecidas, com a mesma função, desde as mais simples às mais complexas. As percepções do problema e os interesses das partes interessadas (empresa e fornecedores) são iguais, pois buscam custos menores e maior lucratividade. Para a empresa, custos menores significam menor preço das peças e para os fornecedores, maior lucro. O problema, então, neste caso, foi uma equação que atendesse aos interesses de ambas as partes, ou seja, a busca do equilíbrio de interesses.

\subsection{MÉTODO/FERRAMENTAS E TÉCNICAS}

Devido ao envolvimento com o problema e como líder de um grupo interfuncional de otimização do valor dos produtos, optou-se pelo uso do estudo de caso com pesquisa-ação, como instrumento de investigação. A pesquisa-ação é um processo que segue um ciclo de meIhoria contínua da prática, através do desempenho das atividades no campo da prática e da investigação a respeito dela. No transcurso do processo da pesquisa-ação, aprende-se mais, tanto sobre a prática, como sobre a investigação.

De acordo com Lüdke e André (1986), o estudo de caso como estratégia de pesquisa pode ser simples e específico ou complexo e abstrato e deve ser sempre bem delimitado. Pode ser semelhante a outros, mas é também distinto, pois tem um interesse próprio, único, particular.

Para Mello (2012), as características desse tipo de pesquisa são que o pesquisador observa, mas também atua no objeto do estudo; há cooperação entre o pesquisador e o pesquisado, abordagem holística, entendimento, planejamento e implementação de mudanças; o pesquisador tem que ter conhecimento prévio do objeto e deve ser conduzida em tempo real.

Segundo Thiollent (2005), o objetivo técnico de uma pesquisa-ação é contribuir para o melhor equacionamento possível do problema 
considerado como central da pesquisa. O objetivo científico, o de obter informações que seriam de difícil acesso por meio de outros procedimentos, visando aumentar o conhecimento (teoria) de determinadas situações.

O processo de investigação-ação se desenvolveu em quatro fases, as quais foram: a fase de identificação do problema, a fase de planejamento de uma solução, a fase de implementação e a fase de monitoramento e avaliação de sua eficácia.

A pesquisa começou, então, pela análise da situação e, paralelamente, no desenvolvimento das atividades, foram ocorrendo as projeções e as implementações das mudanças. As atividades de cada fase do processo de redução da complexidade, desde a formulação das propostas até a sua implementação na produção, foram sendo observadas e avaliadas continuamente. Tendo em vista a melhoria contínua, como objetivo de todo o processo, foram sendo planejadas as soluções dos problemas e foram sendo implementadas as melhores opções de solução. O monitoramento e a avaliação das situações resultantes foram efetuadas, por consequência, assim como a interpretação e a avaliação dos resultados, a fim de planejar novas medidas de melhorias das práticas de gestão. Nesse processo, a reflexão foi essencial e ocorreu durante todo o ciclo. Ao final desse processo, ainda foram aplicados questionários aos participantes do Grupo, com o objetivo de identificar a visão desses em relação ao trabaIho desenvolvido.

\section{RESULTADOS}

\subsection{SITUAÇÕES PROBLEMA IDENTIFICADAS}

Em 2013, foram produzidos, em quatro linhas de montagem, 14 modelos, a uma velocidade de 192 carros por hora, ou 3,2 carros por minuto. A quantidade e variedade de peças previstas para a estruturação ou montagem dos veículos é proporcionalmente crescente, em função da diversidade de versões, motores, opcionais, cores externas e internas. Disso resulta uma infinidade de combinações de veículos que condicionam e vinculam as instalações e os recursos. Há três plataformas de desenvolvimento de produtos: small cars (oito modelos), compact cars (três modelos) e comercial cars (três modelos) e a criação de novos componentes muito parecidos com os existentes é inevitável, devido à customização em massa.

A dificuldade de montagem das peças, conforme os ciclos de montagem, é o problema central resultante dessa situação. Os ciclos de montagem são os manuais com as instruções de montagem. Os desenhos são números que individualizam as peças. O problema do ciclo de montagem é que, muitas vezes, os números de desenhos não são especificados nas folhas de operação, mas, somente as matrículas, que são referências genéricas dos desenhos, sendo iguais para todos os modelos. Quando uma peça, com um determinado número de desenho, não é montada nos carros conforme a documentação técnica e, no seu lugar, é montada outra, acontece o fenômeno do saldo negativo que impacta na gestão dos estoques, sendo isso percebido pelos Analistas de Programação, em suas práticas diárias. As razões são várias e é mais comum de acontecer nos casos de peças similares com a mesma função.

Diante deste contexto foi concebida a criação de um grupo na área de manufatura para reduzir a complexidade da fábrica. Este grupo atuaria com profissionais especialistas de várias áreas da empresa e, na figura 2, está desenhada a estrutura que foi imaginada no momento de sua criação.

O grupo de redução da complexidade, no desempenho de suas atividades, se deparou com outras duas dificuldades, uma no aspecto de estilo e outra no aspecto técnico que, também, fazem aumentar o número de peças e, consequentemente, a complexidade da fábrica.

A demonstração de que a unificação de componentes muito parecidos com a mesma função e que a adoção de menos cores para destacar componentes, visando à simplificação dos processos de produção e de gestão dos materiais, diante dos argumentos das áreas de Enge- 
Figura 2: Estrutura inicial na fase de criação do grupo de redução de complexidade.

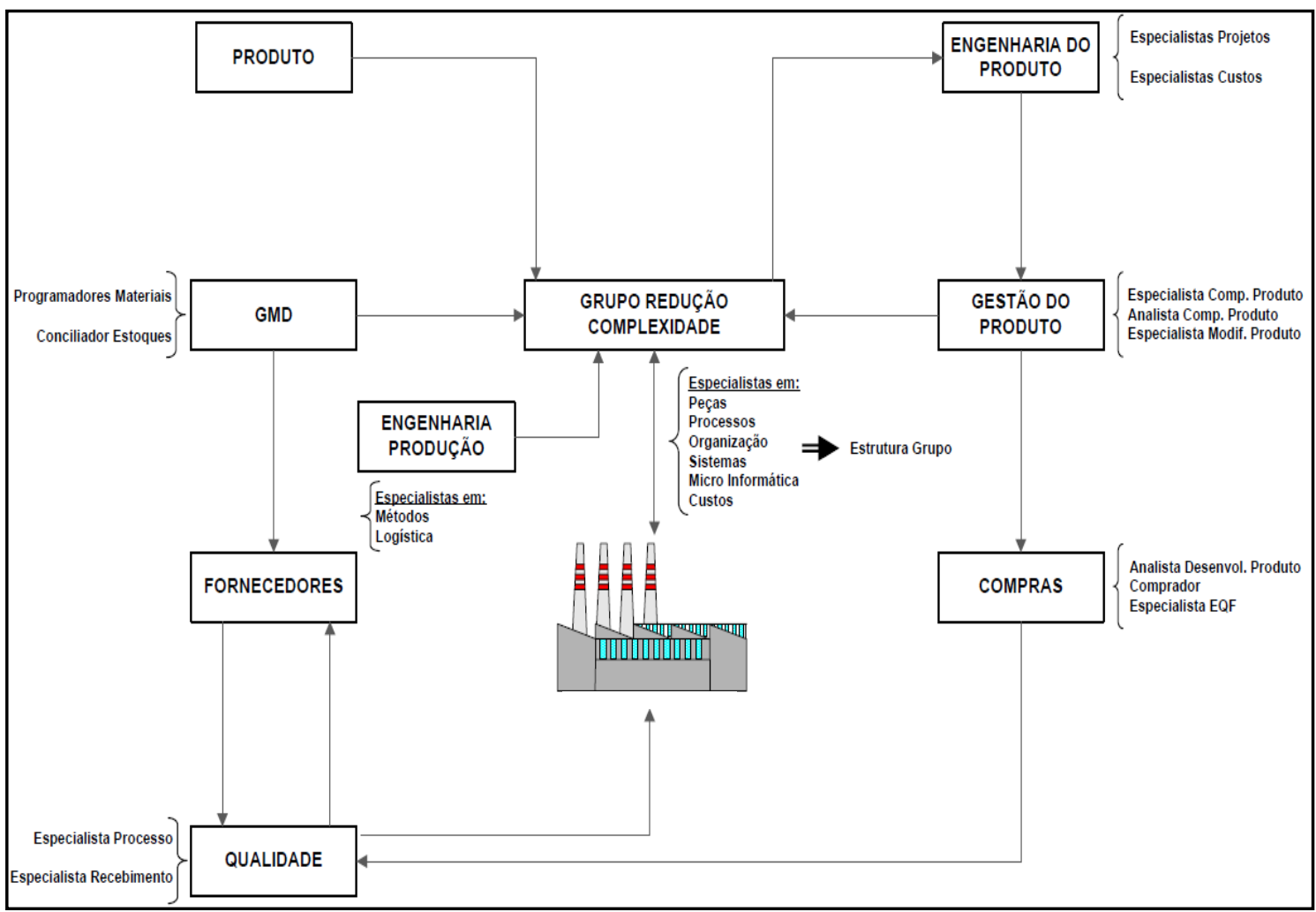

Fonte: Autores.

nharia e do Produto, não é uma tarefa fácil. Mesmo com essa dificuldade, foi possível a redução do número de amortecedores de 163 desenhos para 83, pelo atendimento da solicitação de unificação dos óleos de clima frio e de clima quente, após muitos testes de experimentação pela Engenharia.

Várias situações que representavam oportunidades de simplificação, estão detalhadas a seguir:

1)

Situação anterior: Moldura estética na cor externa do veículo, que gerava um total de 24 painéis de porta diferentes, con- forme Figura 3.

Situação proposta: Usar moldura cromada, reduzindo o número de painéis para 4 apenas.

A aprovação dessa proposta causou impacto positivo na área de compras, que estava efetuando

Figura 3: Componente objeto da Proposta 1.

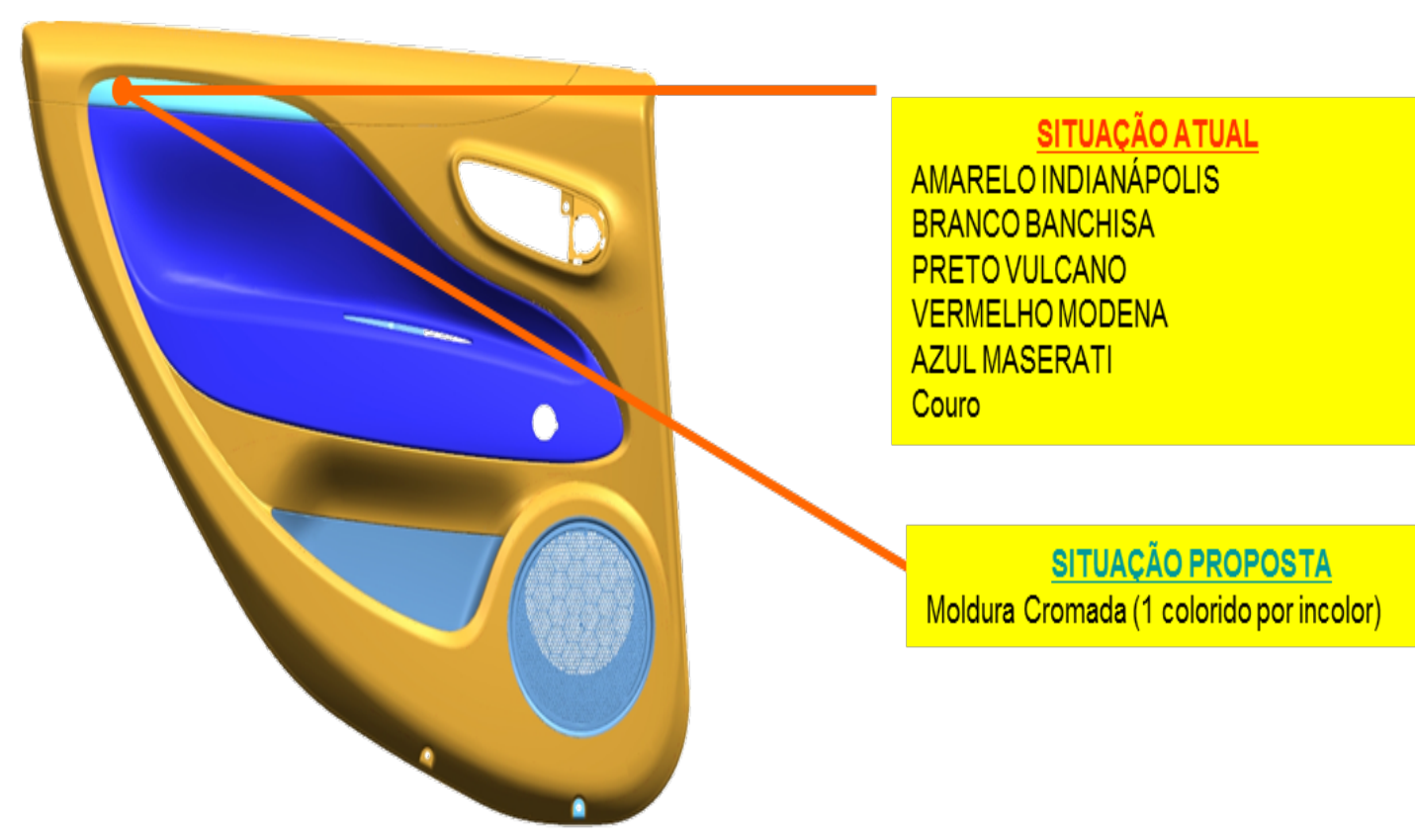

Fonte: Autores. 
tratativas comerciais e a certificação dos processos de construção dos componentes nos fornecedores. Foram eliminadas muitas atividades de cotação, de emissão de pedidos de compras e de apresentação e aprovação de amostras. Na área comercial, o aumento do estoque de peças de reposição nos armazéns foi evitado, assim como foi facilitada a atividade de planejamento das necessidades dessas peças. Essa proposta de padronização do número de desenhos dos painéis de portas comprovou os bons resultados alcançados da proposta de unificação dos óleos dos amortecedores.

2)Situação anterior: Faixa estética (figura 4) central do painel de instrumentos montada internamente somente nos veículos com o opcional air bag, por exigência de montagem do módulo air bag.

Situação proposta: Montar internamente a faixa central também nos veículos com o opcional air bag, incluindo o complemento esquerdo, reduzindo o número de painéis de instrumentos de 4.448 para 2.224.

Essa proposta foi reprovada pelo Diretor Industrial, pois aumentaria o número de homens por veículo, apesar dos benefícios nas atividades dos vários serviços de apoio à oficina, das diretorias de

Figura 4: Componentes objeto da
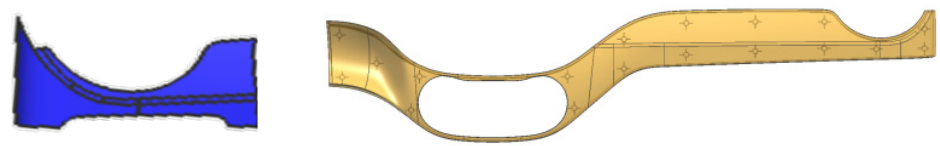

Fonte: Autores

Engenharia, de

Compras, do Financeiro, da Comercial e da Industrial.

3)Situação anterior: Chicotes painel específicos com derivação para o opcional rádio e chicotes painéis específicos com derivação para o opcional comando rádio no volante.

Situação proposta: Chicotes comuns predispostos para as duas funções,reduzindo o número de desenhos de 2.224 para 1.392.

Essa proposta não foi considerada, pela Engenharia do Produto, pois outro opcional, referente ao comando câmbio no volante determinou uma condição técnica que exigiu ainda mais o aumento do número de desenhos dos painéis.

4)Situação anterior: Cores diferentes dos componentes dos painéis de instrumentos entre as ver- sões $2 \mathrm{~V}$ (dois volumes = versão hatch) e $3 \mathrm{~V}$ (três volumes $=$ versão sedan).

Situação proposta: Unificação das cores e consequentemente dos painéis de instrumentos entre as versões, reduzindo o número de desenhos de 1.392 para 1.104 .

Essa Proposta foi reprovada pelo Diretor do Produto, pois envolvia um componente que deveria ser mantido para diferenciar uma versão da outra, sendo necessárias as cores diferentes, entre as versões.

5)Situação anterior 1: Volantes específicos em couro e volantes específicos com comando rádio no volante (Figura 5).

Situação proposta 1: Volantes com comando rádio no volante somente vinculado ao revestimento em couro, reduzindo o número de desenhos de 30 para 18.

Situação anterior 2: Volantes com cores diferentes entre as versões.

Situação proposta 2: Unificar volantes coloridos de uma versão com a outra, reduzindo os desenhos de 18 para 10.

Essas duas propostas não foram aprovadas

Figura 5: Volantes em couro com comando rádio no volante e sem comando.
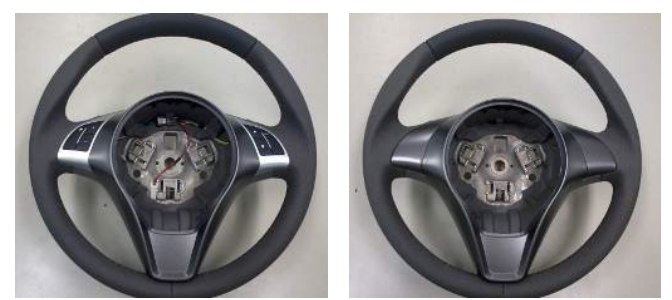

Fonte: Autores.

pelo Produto.

6)Situação anterior: Tampa vão de carga e passador do cinto de segurança em

duas cores diferentes (figura 6).

Situação proposta: Adotar uma só cor para as duas peças. 
Figura 6: Tampa vão de carga e passador do cinto de segurança.
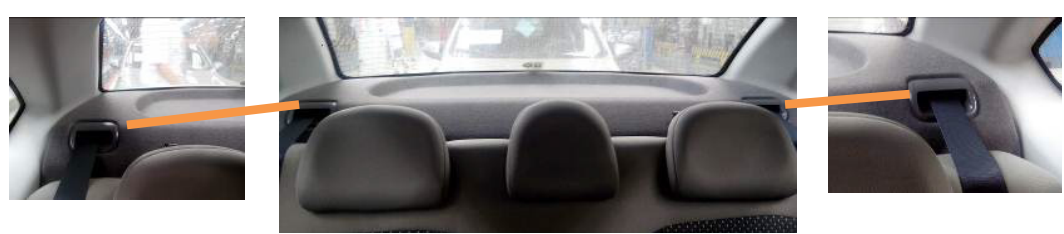

Fonte: Autores.

Essa proposta foi aprovada, pois as peças de cores diferentes não seriam notadas pelos clientes, por se localizarem na parte posterior do veículo.

7)Situação anterior: Elementos de fixação com características muito parecidas usados em várias aplicações.

Situação proposta: Padronizar os elementos já aprovados pelo uso.

As propostas desse tipo, que não alteram as características estéticas, nem impactam nas exigências das áreas de Produto e de Estilo, são mais fáceis de serem aprovadas, pois dependem apenas da formalização dos testes de montabilidade e de funcionalidade.

8)Situação anterior: Moldura interna dos apóia-braços em três cores (figura 7).

Situação proposta: Reduzida uma das cores da moldura, reduzindo o número de desenhos de 18 para 12.

Figura 7: Tampa vão de carga e passador do cinto de segurança.

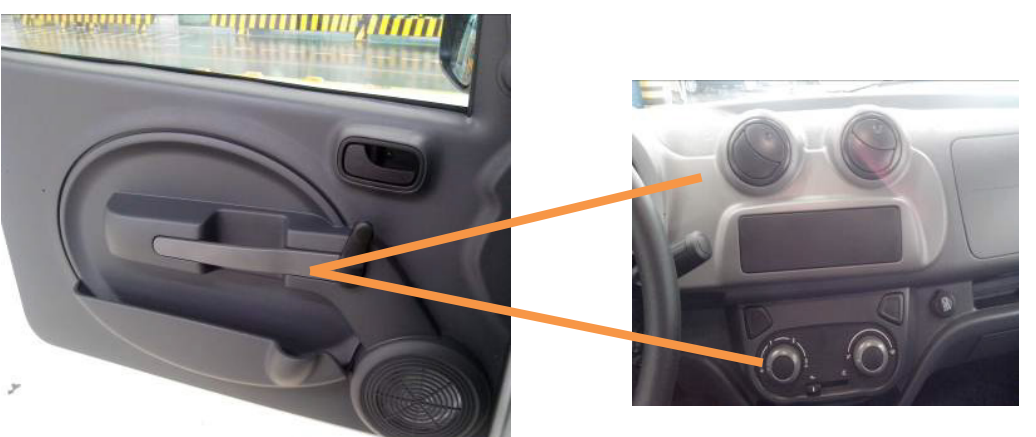

Fonte: Autores.

A aprovação dessa proposta, pelo diretor do Produto, teve um significado especial, menos pelo fato de ter sido a primeira proposta de padronização que foi aprovada, do que por ter quebrado o paradigma de superar um dos fatores críticos que é a razão de estilo que justifica a diversidade de peças em várias cores, como diferencial para atrair clientes.

A padronização não visa impedir a customização, visto que a existência de um design único e personalizado aproxima o consumidor do produto, conforme levantado por Santos e Silveira (2011). No entanto, é necessário que "os esforços sejam voltados para a personalização somente nos pontos em que ela é necessária ou desejada" (Gilmore e Pine, 2000) apud (Santos e Silveira, 2011).

Ressalta-se que a padronização muitas vezes ocorre em componentes não visíveis ao consumidor final, não afetando, portanto, o design do produto. Segundo Quelch et al. (1994) apud Santos e Silveira (2011), a alta variedade de componentes oferece riscos a longo prazo ao promover o excesso de segmentação, o que pode tornar confusa a função estratégica dos produtos.

\subsection{MÉTODO DE REDUÇÃO DA COMPLEXIDADE}

A partir das primeiras situações identificadas e do desenvolvimento de suas soluções, pode-se estabelecer um método a ser aplicado nas demais situações que possam ser apresentadas.

A figura 8 representa o método proposto e implementado por uma equipe interna à empresa, dentro da indústria automobilística.

Para construção do processo de redução da complexidade, a prática das atividades com base no fluxo da informação e na sequência dos marcos definidos seria fundamental. A gestão diferenciada, com base em tempos de exe- 
cução das atividades bem definidas para cada marco, também, seria muito importante, pois esse processo teria um tempo médio de percurso previsível, em torno de 100 dias. Passou-se a usar uma planilha de acompanhamento das propostas, predisposta para registrar as datas de conclusão de cada atividade. Dessa forma, a diferença de uma data do último marco pela do marco anterior forneceria o tempo de execução da atividade. Como se sabe que seria natural a ocorrência de atrasos no desenvolvimento das atividades, se não houver um acompanhamento sistemático e as devidas cobranças, por parte dos responsáveis, esta planilha, com as datas de

Figura 8: Método de simplificação de processos.

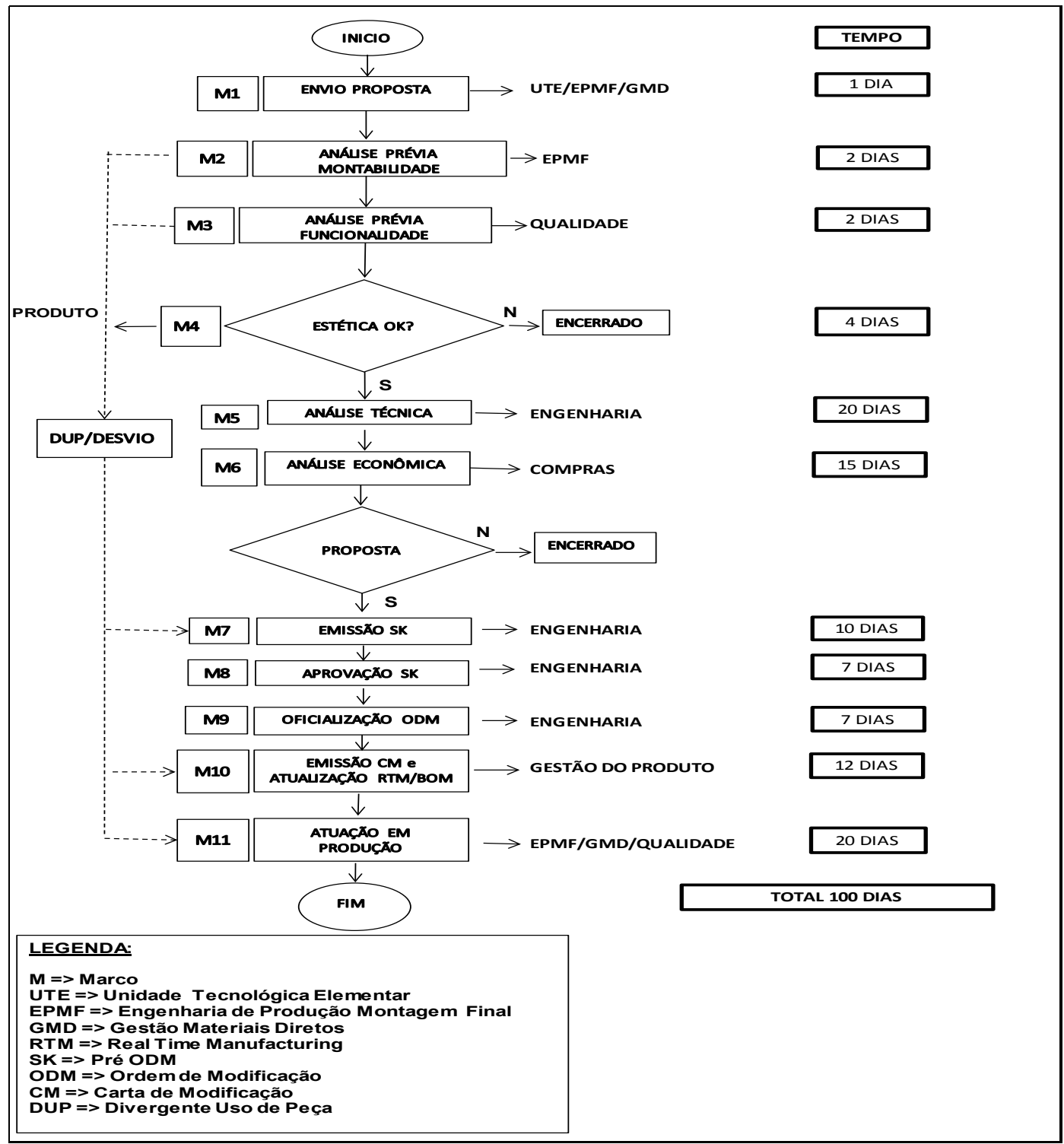

Fonte: Autores. conclusão de cada atividade, poderia ser usada como um eficiente recurso de gestão do processo.

Mudou-se o fluxo do processo inicialmente proposto, para torná-lo mais próximo do modo de proceder, pois percebeu-se que a análise econômica deveria ser efetuada preliminarmente, antes da montabilidade e funcionalidade das peças propostas. O tempo de percurso do processo, que passou para 120 dias, considerando o ciclo preliminar de 30 dias, passou a ser um objetivo a ser perseguido pelo grupo. Foram preparadas várias situações gerenciais de controle do processo, para se obter a previsibilidade de atuação das propostas e a contenção das dispersões em limites mínimos e bem definidos.

Com este método foi possível experimentar uma série de procedimentos e práticas de trabalho vivenciando as dificuldades encontradas nos momentos de desenvolvimento das propostas e de controle e cobrança das conclusões das tarefas, visando a mudança de fase do processo de padronização de componentes.

A CObrança sistemática das 
pendências aos responsáveis foi necessária. Esse ponto passou a merecer uma atenção especial, no sentido de se criar uma consciência coletiva no grupo, em função da importância da redução da complexidade para a empresa e do papel diferenciado que cada integrante do grupo deveria desempenhar para o alcance dos resultados.

\section{CONSIDERAÇÕES FINAIS}

No que se refere às limitações encontradas para a redução da complexidade, pode-se apontar o elevado volume de propostas reprovadas pelos motivos de estilo, técnicos e econômicos; os atrasos, relativamente grandes, na conclusão de tarefas, por parte dos responsáveis não pertencentes ao Grupo. Esses fatores limitadores não estão contribuindo para um resultado melhor, por falta de uma consciência coletiva forte, que ainda não existe, mas que começa a se difundir e espaIhar pela organização aos poucos.

Outros benefícios referem-se que a simplificação de componentes reduz os caminhões nas estradas e, consequentemente, as emissões de poluentes na atmosfera; o fornecedor reduz sua variação; a padronização gera economia de espaço e melhor saturação de caminhões, redução de set up nos fornecedores, redução de consumo de energia, redução da movimentação de máquinas no interior das plantas, redução de consumo de combustível utilizado no transporte in bound.

Em relação às condições necessárias na empresa para a redução da complexidade, pode-se relacionar: maior apoio da Engenharia do Produto, do Marketing e das Compras; a morosidade em implantar as ideias; pouca agilidade de respostas às propostas por parte da Engenharia do Produto; o impedimento do cumprimento das metas devido à análise econômica por parte de Compras, à análise técnica por parte da Engenharia e à análise estética por parte do Produto, reprovando grandes partes das propostas; o ritmo distinto com que caminham as diferentes áreas en- volvidas no processo; as particularidades que cada setor possui e o paradigma de mudar pensamentos que há muito estão alienados com um processo focado mais nas necessidades das próprias áreas do que numa visão geral e sistêmica; os trâmites existentes e as saturações das pessoas em suas respectivas atividades; a falta de conhecimento das áreas envolvidas, gerando falta de comprometimento e falta de autonomia para tomadas de decisões do grupo, referentes a propostas consideradas positivas; a falta de valorização dos ganhos e benefícios da padronização de componentes e reconhecimento das perdas e desperdícios dos componentes com grande semelhança; a necessidade de se adequar a cada nova situação; o aumento de custo e/ ou divergências da redução da complexidade com interesses da área do Produto, o que inviabiliza a unificação de componentes; a burocratização dos processos e o atraso no retorno das áreas envolvidas.

\section{REFERÊNCIAS}

CAMPOS, Vicente Falconi. Gerenciamento da rotina do trabalho do dia-a-dia. 7.ed. BELO HORIZONTE: EDG, 1999. 276p

COELHO, Carlos Daniel Pinto. A simplificação dos processos de produção e de gestão de materiais diretos na indústria automobilística: Um estudo de caso de uma montadora de veículos. Repositório de Conteúdo Digital da UFSC, 2013, 105 p. Dissertação de mestrado em Engenharia Ambiental Profissional. Universidade Federal de Santa Catarina, Florianópolis. Disponível em: <https://repositorio.ufsc.br/ bitstream/handle/123456789/106944/318376. pdf? sequence $=1>$

DEMING, E., org.Out of Crisis. Cambridge, MIT, 1986.

HUBBARD, Douglas W.. Como Mensurar Qualquer Coisa - Encontrando o Valor do que É Intangível nos Negócios. 1. Ed. Tradução Ebreia 
de Castro Alves. Qualitymark, 2009. 376p.

LUDKE, M e ANDRÉ, M. Pesquisa em educação: abordagens qualitativas. São Paulo, EPU, 1986.

MELLO, Carlos. Métodos Qualitativos: Pesquisa-ação. Aula 11. Disponível na internet por http em: <http://www.carlos.mello.unifei. edu.br/Disciplinas/Mestrado/PCM-10/Slides-Mestrado/Metodologia_Pesquisa_2012-Slide_Aula_11_Mestrado.pdf> Acesso em 11 ago. 2014

MORIN, Edgar. Introdução ao Pensamento Complexo. Porto Alegre: Sulina, 2006.Revista Auto Esporte. Aceleramos, PRIMEIRA VOLTA. Dodge Dart, Ed. Globo, Junho/2012. P. 46 a 50.

SANTOS, Flávio Anthero Nunes Vianna. SILVEIRA, Túlio César Lenzi. Relações entre a customização em massa e o design de produtos industriais. Florianópolis: Sistema e Gestão Revista Eletrônica, 2011. Disponível na internet por http em: <www.uff.br/sg/index.php/ sg/article/download/.../V6N4A2> Acesso em 13 ago. 2014

SLACK, Nigel, CHAMBERS, Stuart, JOHNSTON, Robert. Administração da Produção. 2. Ed. Tradução Maria Tereza Corrêa de Oliveira, Fábio Alher. Revisão Técnica Henrique Luiz Corrêa. São Paulo: Atlas, 2002. 750p.

THIOLLENT, M. Metodologia da Pesquisa-ação. 14 ${ }^{\mathrm{TM}}$ edição. São Paulo: Cortez Editora,2005.

WIEMES, Leandro; BALBINOTTI, Giles. A padronização de processo produtivo em uma indústria automobilística: uma análise teórico prática. Gestão e Tecnologia Industrial. Belo Horizonte, mai. 2009. Seção artigos. Disponível na internet por http em: <http://www. techoje.com.br/site/techoje/categoria/detaIhe_artigo/855> Acesso em: 12 ago. 2014 